\title{
Editorial: The Marine Carbon Cycle: From Ancient Storage to Future Challenges
}

\author{
C. März ${ }^{1 *}$, P. G. Butler ${ }^{2}$, G. D. O. Carter ${ }^{3}$ and I. T. E. Verhagen ${ }^{4}$ \\ ${ }^{1}$ School of Earth and Environment, University of Leeds, Leeds, United Kingdom, ${ }^{2}$ College of Life and Environmental Sciences, \\ University of Exeter, Cornwall, Unted Kingdom, ${ }^{3}$ British Geological Survey, The Lyell Centre, Edinburgh, United Kingdom, \\ ${ }^{4}$ Department of Earth, Ocean and Ecological Sciences, University of Liverpool, Liverpool, United Kingdom
}

Keywords: carbon, ocean, sediment, climate-change, storage

\section{Editorial on the Research Topic}

The Marine Carbon Cycle: From Ancient Storage to Future Challenges

Understanding the oceanic carbon cycle, its dynamics, and its historical and future trajectories is key to our ability to model future climate change. With this in mind, the second Shackleton conference, held in September 2019 at the Geological Society of London (GSL), and organized by the Marine Studies Group of the GSL, focused on oceanic carbon storage, specifically the dynamic processes by which carbon is permanently removed from the atmosphere and/or the terrestrial lithosphere and biosphere and stored in coastal and marine sediments.

The publications in this Research Topic mainly cover two important and emerging aspects of carbon storage in marine sediments: First, the increasing recognition of the seafloor as a "blue carbon" store (sensu lato) where organic material from the surface ocean or from land is buried over long timescales and thus removed from the ocean-atmosphere system acting as a negative feedback on atmospheric $\mathrm{CO}_{2}$ concentrations. Second, in any marine environment a certain fraction of the sedimentary organic matter is degraded by microbes, and the dissolved inorganic carbon produced in this process can subsequently, given the right conditions, be precipitated into authigenic carbonate minerals that retain the carbon within the seafloor.

The "blue carbon" contributions highlight how very different environments can serve as important carbon storages, but both highlight the importance of appropriate methods to be applied in order to assess the true blue carbon stocks in these environments. The manuscript by Vaughn et al. focuses on the dynamic, marginal marine salt marshes and wetlands of Florida, making the important point that these carbon stores are highly dynamic, responding in a complex manner to, e.g., sea level rises and flooding of previously terrestrial areas. The key point being that unless the entire section of potentially carbon-containing deposits is assessed, and spatial heterogeneity is taken into account, carbon stock estimates are bound to be inaccurate. Following a different approach, Smeaton et al. aim to generate large-scale maps of sedimentary carbon stocks for the North Sea, using a combination of discrete point analyses of various chemical and physical properties of the sediment, geophysical measurements of seabed characteristics, and a statistical framework to link both approaches. This work shows great promise for estimating carbon stocks in surface sediments over large continental shelf areas if they have a solid data coverage. Taken together, these manuscripts join a growing body of literature that seeks to estimate not just the stocks of carbon residing in the seabed, but also its vulnerability as well as economic value in terms of "carbon credits." 
The "authigenic minerals" contributions expand on the carbon storage issue, reminding us of the long-established fact that any organic material within the seabed, depending on its reactivity, will undergo some degree of degradation. The question is then what happens to the carbon stored in this organic matter. The manuscripts in this Research Topic focus on the "ideal scenario" from a carbon storage perspective, i.e., the dissolved inorganic carbon produced during organic matter degradation gets re-sequestered into authigenic carbonates. First, Turchyn et al. explores the precipitation dynamics of authigenic carbonates using an invaluable and truly global compilation of pore water data generated over decades by the International Ocean Discovery Program (IODP, and its predecessors ODP and DSDP). They confirm, on a global scale, that the microbial reduction of sulphate driven by organic matter degradation leads to conditions favorable for carbonate precipitation, in particular if it is coupled with the anaerobic oxidation of methane. In addition, methane itself in the sediment appears to increase the potential for carbonate formation in the sediment, and this might be related to the weathering of silicate minerals below the seafloor, a process that is well-documented to consume $\mathrm{CO}_{2}$ during weathering on land. This manuscript shows that elegant and thought-provoking research can be conducted if large and relatively "simple" (but high-quality) data sets are statistically evaluated in a way that is based in the understanding of underlying biogeochemical processes. In the final manuscript of the Research Topic by James et al., such processes are further explored using state-of-the-art analytical techniques, namely calcium isotopes in pore waters of marine sediments. This relatively new isotope system allows to explore and trace the processes involved in authigenic carbonate precipitation from a new perspective. The manuscript finds that in a biogeochemical system where authigenic carbonate precipitation can be expected, the calcium isotope system does not show the significant response that should result from this process. This is a very interesting example of how the application of new isotope systems can reveal that certain biogeochemical processes, like carbonate precipitation, can be more complex than is traditionally perceived using non-isotope data. In other words, this study does not necessarily and unequivocally answer the original scientific question, but opens a new set of questions that we would not even know needed to be asked if it were not for the new isotope data. It is such unexpected and thought-provoking findings that drive research into the marine carbon cycle.

In summary, despite being one of the best-studied element cycles in geochemistry, the marine carbon cycle remains mysterious, challenging, and a fascinating topic that will require further interdisciplinary research, as well as links to its societal relevance, for years to come. This science is necessary in order to reveal some of the most important feedback processes in the Earth system that control how our planet's climate, and our society, will develop in the future.

\section{AUTHOR CONTRIBUTIONS}

$\mathrm{CM}$ wrote the Editorial with input from PB, GC, and IV.

Conflict of Interest: The authors declare that the research was conducted in the absence of any commercial or financial relationships that could be construed as a potential conflict of interest.

Publisher's Note: All claims expressed in this article are solely those of the authors and do not necessarily represent those of their affiliated organizations, or those of the publisher, the editors and the reviewers. Any product that may be evaluated in this article, or claim that may be made by its manufacturer, is not guaranteed or endorsed by the publisher.

Copyright (c) 2021 März, Butler, Carter and Verhagen. This is an open-access article distributed under the terms of the Creative Commons Attribution License (CC BY). The use, distribution or reproduction in other forums is permitted, provided the original author(s) and the copyright owner(s) are credited and that the original publication in this journal is cited, in accordance with accepted academic practice. No use, distribution or reproduction is permitted which does not comply with these terms. 